\title{
Comparison of Different Anesthetic Protocols for Morphometric Measurements of Carp (Cyprinus carpio)
}

\author{
Ferhat Çağiltay ${ }^{1}$, Alexander Atanasoff*2, Mehmet Sağlam ${ }^{3}$, Soner \\ Çağatay ${ }^{3}$, Galin Nikolov $^{3}$, Okan Ekim $^{2}$, Faik Sertel Seçer ${ }^{4}$ \\ ${ }^{1}$ Faculty of Fisheries, Istanbul University, Ordu caddesi 200, 34031 Istanbul,Turkey \\ 2 Trakia University, Students` campus 2, 6014 Stara Zagora,Bulgaria \\ ${ }^{3}$ Faculty of Veterinary Medicine, Ankara University, Ankara,Turkey \\ ${ }^{4}$ Faculty of Agriculture, Trakia University, Students' campus 2, 6014 Stara Zagora,Bulgaria \\ ${ }^{5}$ Fisheries and Aquaculture, Faculty of Agriculture, Ankara University, Ankara, Turkey
}

\begin{abstract}
Measurement of growth performances in fish is carried out in stressful and unnatural environment. The purpose of the present investigation was to compare the effect of four different water-borne anesthetic agents. The fish (Ave. wt. $400.3 \pm 7.12 \mathrm{~g})$ were divided into four groups in the glass tanks $(80 \times 48 \times 30 \mathrm{~cm})$ containing $80 \mathrm{~L}$ of dechlorinated bore water. For the first group we used clove oil $(\mathrm{CO})$ and anesthetic agents used for other three groups were as follows: second group- lidocaine 1\% (LC), III groupisoflourane (IF), IV group-halothane (HT). During experiment, water quality parameters (to, $\mathrm{pH}, \mathrm{O}_{2}$, and $\mathrm{NO}_{3}$ ) were recorded. The desired concentration of anesthetics was established andinduction time, maintenance and recovery time were recorded. In two groups out of four (LC and HT) time of induction was longer approximately with 1 minute and time of recovery was shorter with 30 seconds in comparison with other two groups (CO and IF) where the time for both was 3 minutes. It could be concluded that the anesthetic time for each of the protocols used was about 4-5 minutes and allowed to measure the growth performance. An effective and safe agent is $1 \%$ lidocaine used as a water-based anesthetic at $100 \mathrm{mg} \cdot \mathrm{L}^{-1}$. Isoflurane can be used with caution in small carp because there is a risk of overdose. We recommend the anesthetic clove oil protocol.
\end{abstract}

Key words: carp, clove-oil, lidocaine, isoflourane, halothane.

\section{Introduction}

In fish practice, an anesthesia of fish is using to avoid any damage and lower the stress during handling (transport, examination, measurement of growth performance, artificial reproduction, biopsy etc.) $[1,2,3,4,5]$. The most widely method for administration of anesthetics who is analogous to gaseous anesthesia is water-borne anesthesia [6]. In general, water-borne agents are more easily administered to produce effect and the depth of anesthesia may be changed by using solutions

\footnotetext{
* Corresponding author: Alexander Atanasoff, hmi atanasoff@mail.bg
}

(c)) BY-NC-ND $\odot 2017$ Ferhat Çağiltay et al., published by De Gruyter Open. This work was licensed under the Creative Commons Attribution-NonCommercialNoDerivs 3.0 License with different concentration of the anesthetic agent. More of the analgesic, sedative or anesthetic drugs used in aquaculture are similar to those used in vertebrates' animal or humans [7, 8]. The drug molecules diffuse rapidly into the blood across the secondary lamellae of gills, which drain into the efferent arterial blood from where the route to the central nervous system is very short. Most anesthetic drugs are excreted predominantly through the gills [6], but the liver, kidneys and skin may play roles in metabolism and excretion too. Species may differ widely in their response to anesthetics, screening of their use is necessary.

The purpose of the present investigation is to compare the effect of four different anesthetic 
agents used in human and veterinary medicine for measurement of growth performance in carps.

\section{Material and Methods}

The present study was conducted in accordance with the Law on Veterinary and Medical Activities and Animal Welfare Act and approved by the Committee on Animal Experimentation at the Trakia University, Stara Zagora, Bulgaria.

Forty carp were held in an $80 \mathrm{~L}(80 \times 48 \times 30 \mathrm{~cm})$ glass tanks of Experimental Aquaculture Base, Faculty of Agriculture, Trakia University. Four experimental groups of fish were established, each containing ten fish. Water temperature $\left({ }^{\circ} \mathrm{C}\right)$, dissolved oxygen $\left(\mathrm{mg} \cdot \mathrm{L}^{-1}\right)$, nitrate $\left(\mathrm{mg} \cdot \mathrm{L}^{-1}\right)$ and active acidity were demand for $1 \mathrm{~h}$ with a digital thermometer while dissolved oxygen, nitrate concentration and $\mathrm{pH}$ were determined using WTW-oxi330, HANNA HI 98312 and REDOX Zac plus.

Prior to anesthesia, food was withheld for 24 hours to minimize the risk of regurgitation. The desired concentration of anesthetic agents was established and induction time, maintenance and recovery time were recorded.

Induction time was recorded from adding the anesthetic agent to the water till no voluntary swimming, decreased respiratory rate and muscle tone and weak response to strong tactile stimuli were observed. Time of maintenance was recorded from connecting the non-recirculating system till the last measurement, which was the same for all groups- 5 minutes. Time of recovery was recorded from placing the fish in the anesthetic-free water tank till respiratory rate increases, muscle tone returns, and the fish swims with progressively less ataxia until full equilibrium is regained.

For the first group, clove oil (CO) (clove bud, Eterika $\circledast$, Bulgaria) containing eugenol as active ingredient was used. The stock solution was added directly to the water at concentration of 40 $\mathrm{mg} \cdot \mathrm{L}^{-1}$ water and thoroughly mixed. In the group II, (LC) $1 \%$ lidocaine (Vetprom $®$, Bulgaria) at a dose of $100 \mathrm{mg} \cdot \mathrm{L}^{-1}$ water was added by mixing lidocaine solution with the water. Total dose at $8 \mathrm{~g}$ $1 \%$ lidocaine was calculated and total volume of $800 \mathrm{ml}$ was used. In the last two groups (III and IV) fluorinated hydrocarbons such as isoflurane (IF) (Terrel $\circledast$, Minday Inc, USA) and halothane (HT) (Narcotan $\AA$, Spofa, Czech Republic) were respectively used by direct addition to water. This was achieved by spraying it through a hypodermic needle (25G) under the water surface. The concentration for both anesthetics was $1.5 \mathrm{mg} \cdot \mathrm{L}^{-1}$ water. The depth of anesthesia was monitored by observing the behaviour of the fish in water. In our study we used the following criteria: voluntary swimming, reaction to visual and tactile stimuli, and response to postural changes, jaw tone and respiratory rate by the method descripted by Iwama et al. [9].

Out of water, fish handling and growth performances were measured by wearing latex gloves to minimize damage to the skin and mucus covering. Fine mesh nets were used for catching and after induction the carps were placed on a nonabrasive surface, such as waterproof drape to prevent damage to delicate piscine cuticle. During measurement of growth performance anesthesia was maintained by intravenous fluid container, containing anesthetic solution by non-recirculating anesthetic system. The control valve was used to regulate the flow at about $40 \mathrm{ml}$ per min. This solution was aerated using an airstone and was applied through the mouth, so that water passed over the gills and out through clefts in the operculum. The flow was normograde to achieve optimal gas and anesthetic exchange.

\section{Results and Discussions}

During the study, the mean water temperature

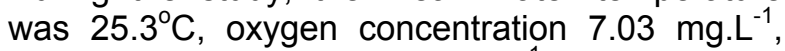
nitrate concentration $0.12 \mathrm{mg}^{-1}$, and $\mathrm{pH} 7.36$ respectively. All were within the technologically allowed ranges for the species.

Induction time for all groups was recorded as followed: for group I - $185.30 \pm 5.65 \mathrm{sec}$., for group

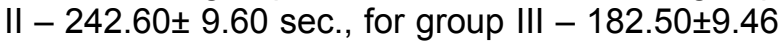
sec., and for group IV $-241.50 \pm 12.03 \mathrm{sec}$. Out of water period for all groups during linear measurement for growth performances was $5 \mathrm{~min}$. On completion of the last procedure all fish were returned immediately in tanks with anesthetic-free aerated water. Respiration, equilibrium and motion were closely monitored during recovery. Recovery time for all groups was recorded as follows: group I - 437.80 \pm 24.56 sec., group II $383.70 \pm 20.17$ sec., group III $-435.33 \pm 22.37$ sec., and group IV - $392.30 \pm 20.82 \mathrm{sec}$. (Table 1).

The smallest fish in group IF (Carp 2) after the measurement showed total loss of equilibrium, decreased respiratory rate and muscle tone, unresponsiveness to strong tactile stimuli. An attempt for resuscitation was made by facing the fish into the flow of aerator in the recovery tank with anesthetic-free water whilst holding the mouth open. Shortly after, cessation of opercular movement was observed and the fish has died. In two groups (LC and HT) the time of recovery and time of induction were significantly different in comparison with same parameters with another two groups (CO and IF). 
Anesthesia monitoring parameters (Mean $\pm S D ; n=10$ in each group)

Table 1

\begin{tabular}{|l|c|c|c|c|}
\hline & $\begin{array}{c}\text { Group I } \\
\text { (clove oil) }\end{array}$ & $\begin{array}{c}\text { Group II } \\
\text { (lidocaine) }\end{array}$ & $\begin{array}{c}\text { Group III } \\
\text { (isoflurane) }\end{array}$ & $\begin{array}{c}\text { Group IV } \\
\text { (halothane) }\end{array}$ \\
\hline $\begin{array}{l}\text { Respiratory rate } \\
\text { prior to anesthesia, } \text { min }^{-1}\end{array}$ & $46.40 \pm 4.195$ & $44.50 \pm 3.749$ & $45.80 \pm 4.185$ & $43.30 \pm 4.296$ \\
\hline $\begin{array}{l}\text { Respiratory rate } \\
\text { 1 min post anesthesia, } \text { min }^{-1}\end{array}$ & $91.30 \pm 9.696$ & $92.60 \pm 9.204$ & $92.50 \pm 11.540$ & $88.50 \pm 8.489$ \\
\hline $\begin{array}{l}\text { Respiratory rate } \\
\mathbf{5} \text { min post anesthesia, } \text { min }^{-1}\end{array}$ & $80.10 \pm 10.354$ & $75.50 \pm 10.480$ & $78.50 \pm 8.462$ & $80.20 \pm 9.402$ \\
\hline $\begin{array}{l}\text { Respiratory rate } \\
\mathbf{1 0} \text { min post anesthesia, } \text { min }^{-1}\end{array}$ & $46.50 \pm 6.819$ & $41.60 \pm 5.481$ & $41.90 \pm 3.900$ & $39.50+1.958^{*}$ \\
\hline Induction time, s & $185.30 \pm 5.65$ & $\begin{array}{c}242.60 \pm 9.60^{* * *} \\
\# \# \#\end{array}$ & $182.50 \pm 9.46$ & $\begin{array}{c}241.50 \pm 12.03^{* * *} \\
\# \# \#\end{array}$ \\
\hline Recovery time, s & $437.80 \pm 24.56$ & $\begin{array}{c}383.70 \pm 20.17^{* * *} \\
\# \# \#\end{array}$ & $435.33 \pm 22.37$ & $\begin{array}{c}392.30 \pm 20.82^{* * *} \\
\# \# \#\end{array}$ \\
\hline
\end{tabular}

${ }^{*} p<0.05 ;{ }^{* * *} p<0.001$ vs clove oil; \#\#\# $p<0.001$ vs isoflurane

The growth performance of carp (Mean $\pm S D ; n=10$ in each group)

Table 2

\begin{tabular}{|l|c|c|c|c|}
\hline \multicolumn{1}{|c|}{ Parameter } & $\begin{array}{c}\text { Group I } \\
\text { (clove oil) }\end{array}$ & $\begin{array}{c}\text { Group II } \\
\text { (lidocaine) }\end{array}$ & $\begin{array}{c}\text { Group III } \\
\text { (isoflurane) }\end{array}$ & $\begin{array}{c}\text { Group IV } \\
\text { (halothane) }\end{array}$ \\
\hline Body weight, kg & $51.02 \pm 8.02$ & $53.00 \pm 8.14$ & $53.41 \pm 8.83$ & $55.83 \pm 9.55$ \\
\hline Maximum length, cm & $13.86 \pm 0.54$ & $13.76 \pm 0.56$ & $13.64 \pm 0.62$ & $14.67 \pm 0.61$ \\
\hline Minimum length, cm & $11.30 \pm 0.43$ & $11.24 \pm 0.46$ & $10.98 \pm 0.48$ & $12.20 \pm 0.51$ \\
\hline Body height, cm & $4.14 \pm 0.22$ & $4.14 \pm 0.22$ & $4.23 \pm 0.23$ & $4.78 \pm 0.26$ \\
\hline Radius, cm & $10.72 \pm 0.40$ & $10.76 \pm 0.40$ & $10.77 \pm 0.54$ & $10.92 \pm 0.44$ \\
\hline
\end{tabular}

Growth performances for each fish were measured according to the methods described by Todorov and Ivancheva [5] and evaluated by a group of anatomist and aquaculture engineer. Body weight, maximum length, minimum length, body height, and radius were recorded (Table 2 ).

In last decade different anesthetics protocols are used to aid for many procedures and measurements of fish [11]. In this study four different group of anesthetics to carp are investigated from the point of view use as an anaesthetizing baths.

One of the most widely used anesthetic agents for fish is clove oil, which is readily available, low cost, without prescription and no risk to human health [2]. Our results about clove oil properties such as time of induction and recovery were the same as those described by a number of researchers $[11,7,12]$ and its advantages such as increased safety for fish compared to other immersion drugs [13].

Carrasco et al. [14] reported that efficacy of lidocaine for carp was $350 \mathrm{mgL}^{-1}$ at $53 \mathrm{sec}$ induction and $780 \mathrm{sec}$ recovery time and lidocaine may be used as a water-borne anesthetic. In another study [15] lidocaine yields variable results as an immersion anesthetic but $100 \mathrm{mg} \cdot \mathrm{L}^{-1}$ lidocaine could be used in the rapid anesthesia (from 5-10 min) with a survival percentage 100\%. Our data revealed that $1 \%$ lidocaine used as a water-borne anesthetic at $100 \mathrm{mg} \cdot \mathrm{L}^{-1}$ water was an efficient and safe agent with relatively rapid induction time and short time of recovery. However the relative difference may be attributed to species difference and water quality characteristics.

There are few published studies evaluating chlorofluorocarbon-based anesthetics in fish $[13,16]$. It was reported that isoflurane is considered safe and effective in freshwater and marine fish at concentrations ranging from $0.4 \mathrm{cc}$ to $0.75 \mathrm{cc}$ isoflurane per $\mathrm{I} \mathrm{H}_{2} \mathrm{O}$ for induction and $0.25 \mathrm{cc}$ isoflurane per $\mathrm{I} \mathrm{H}_{2} \mathrm{O}$ for maintenance [16]. In present study, isoflurane caused death in the smaller fish, thus we suggest this drug to be used with caution in small carps. In our view this was provoked by higher concentrations in some areas due to incomplete solubility in water, which resulted in over dosage.

The results of this experiment are consistent with data [4] showing that halothane provides a rapid induction and good surgical anesthesia with 
excellent maintenance and fast recovery (4-6 $\min$ ). Despite these properties, the use of these agents has a number of disadvantages. Various authors $[17,6]$ have pointed out that volatilization and difficulty in scavenging waste gas is a hazard to the personnel. Given the disadvantages associated with the use of isoflurane and similar drugs, a number of researchers and clinicians recommend them only as a last option for anesthesia, for euthanasia, or not at all. Most fish fully recovered from inhalation anesthetics within 5-8 minutes. Recoveries longer than 10 minutes indicate an excessive anesthetic dose or a compromised animal [18, 16]. In comparison, recovery from oral and parenteral agents is more variable.

Our results showed that in group II and IV, using $1 \%$ lidocaine and halothane respectively, time of induction was statistically significantly longer and recovery was shorter in comparison with other two groups (I and III), using clove oil and isoflurane where the time for both was equal.

\section{Conclusions}

The anesthetic time for each of the protocols used was about 4-5 minutes and allowed to measure the growth performance.

We recommend that isoflurane be used with caution in small carp because there is a risk of overdose.

An effective and safe agent is $1 \%$ lidocaine used as a water-based anesthetic at $100 \mathrm{mg} \cdot \mathrm{L}^{-1}$, it provides good anesthesia with a relatively rapid induction and rapid recovery.

We recommend the anesthetic clove oil protocol from the point of view of the effectiveness of anesthesia, fish welfare, environmental safety and economic effect.

\section{References}

1. Cooke, S., Suski, C., Ostrand, K., Tufts, B. \& Wahl, D. (2004). Behavioral and physiological assessment of low concentrations of clove oil anesthetic for handling and transporting largemouth bass (Micropterus salmoides), Aquaculture, 239, 509529. DOI: 10.1016/j.aquaculture.2004.06.028

2. Feng, G., Zhuang, P., Zhang, L., Kynard, B., Shi, X., Duan, M., Liu, J. \& Huang, X. (2011). Effect of anaesthetics MS-222 and clove oil on blood biochemical parameters of juvenile Siberian sturgeon, J. Appl. Ichthyol., 27, 2, 595-599. DOI: 10.1111/j.14390426.2011.01711.x.

3. Myszkowski, L., Kamiński, R. \& Wolnicki, J. (2003). Response of juvenile tench (Tinca tinca) to the anesthetic 2-phenoxyethanol. J. Appl. Ichthyol., 19, 3, 142-145. DOI: 10.1046/j.1439-0426.2003.00460.x.

4. Ross, L. \& Ross, B. (2008). Anesthetic and sedative techniques for aquatic animals, Blackwell Science Publisher, Oxford.
5. Todorov, M. \& Ivancheva, E. (1992). Manual of practical training in fish farming, Zemizdat Publisher, Sofia

6. Ross, L. (2001). Restraint, anesthesia and euthanasia. In: W Wildgoose (Eds.) Manual of ornamental fish. BSAVA, Quedgeley, Gloucester.

7. Kamble, A., Saini, V. \& Ojha, M. (2014). The efficacy of clove oil as anesthetic in common carp (Cyprinus carpio) and its potential metabolism reducing capacity, Internat. J. of Fauna and Biological Studies, 1, 6, 1-6.

8. Dunn, R. \& Koester, D. (1990). Anesthetics in elasmobranchs: A review with emphasis on halothaneoxygen-nitrous oxide, J. Aquaricult. Aquat. Sci., 5, 3, 44-52.

9. Iwama, G., Mc Geer, J. \& Pawluk, M. (1989). The effects of five anesthetics on acid-base balance hematocrit blood gases cortisol and adrenaline in rainbow trout, Can. J. Zool., 67, 8, 2065-2073. DOI: 10.1139/z89-294

10. Gholipour Kanani, H. \& Ahadizadeh, S. (2013). Use of propofol as an anaesthetic and its efficacy on some haematological values of ornamental fish (Carrassius auratus), Springer plus, 2, 1, 1-5. doi: 10.1186/2193-1801-2-76.

11. Bressler, K. \& Ron, B. (2004). Effect of anesthetics on stress and the innate immune system of gilthead bream (Sparus aurata), Israeli J. Aquacult., 56, 1, 5-13. DOI: http://hdl.handle.net/10524/19093

12. Marking, L. \& Meyer, F. (1985). Are better anaesthetics needed in fisheries? Fisheries, 10, 1, 2-5. DOI: $10.1577 / 1548$ 8446(1985)010<0002:ABANIF>2.0.CO;2.

13. Detar, J. \& Mattingly, H. (2005). Response of Southern Redbelly dace to clove oil and MS-222: Effects of anesthetic concentration and water temperature, Proceedings of the Annual Conference Southeastern Association of Fish and Wildlife Agencies, Saint Louis, 219-227.

14. Carrasco, S., Sumano, H. \& Navohro-Fierro, R. (1984). The use of lidocaine-sodium bicarbonate as an anesthetic in fish, Aquaculture, 41, 4, 161-163. DOI: 10.1016/0044-8486(84)90207-2

15. Abbas, H., Abdel-Gawad, A. \& Akkr, A. (2006). Toxicity and efficacy of lidocaine as an anesthetic for Nile Tilapia (Oreochromis niloticus), Pakistan Journal of Biological Sciences, 9, 12, 2236-2242. DOI: 10.3923/pjbs.2006.2236.2242.

16. Stetter, M. (2001). Fish and amphibian anesthesia. In: D Heard (Eds.) Veterinary clinics of North America: Exotic animal practice, WB Saunders, Philadelphia.

17. Harms, C. (2003). Fish. In: M Fowler R Miller (Eds.) Zoo and Wild Animal Medicine. WB Saunders, Saint Louis.

18. Crosby, T., Hill, J., Watson, C. \& Yanong, R. (2006). Effects of tricaine methanesulfonate, hypno, metomidate, quinaldine, and salt on plasma cortisol levels following acute stress in threespot gourami (Trichogaster trichopterus), J. Aqua Anim. Health, 18, 1, 58-63. DOI: 10.1577/H05-026.1. 